\title{
Real Options Valuation Applied to Transmission Expansion Planning
}

\author{
S. Lumbreras, D.W. Bunn, A. Ramos, M. Chronopoulos
}

\begin{abstract}
Transmission Expansion Planning (TEP) is a complex problem where building a new line involves a long permitting process of around 10 years. Therefore, transmission expansion must anticipate the evolution of uncertainties particularly those derived $f$ by changes in the capacity and location of new generating facilities. As it is not possible to request permits for all possible lines, priorities must be established. We develop a formulation to use Real Options Valuation (ROV) to evaluate the potential benefit of candidate lines and thereby identify priority projects. We present a feasible representation of optionality in TEP projects and propose a tractable evaluation of option value. The proposed technique identifies the candidate transmission lines with the highest potential, as well as their main value drivers. This is implemented on a realistic case study based on the Spanish system.
\end{abstract}

Index Terms - Power Transmission, Circuit Optimization, Mathematical Programming

\section{INTRODUCTION}

$T^{r}$ ransmission Expansion Planning (TEP), conventionally defined as the problem of "deciding which new lines will enable the system to satisfy forthcoming loads with the required degree of reliability" (Kaltenbach, Peschon, \& Gehrig, 1970), is a key element of power systems strategy. As such, it has received considerable attention in the academic literature (Latorre, Cruz, Areiza, \& Villegas, 2003). Despite the extensive nature of this research, the topic remains challenging in both methodology and practice. This is mainly due to the inevitable need for approximation methods in formulation and pragmatic approaches in practice. To envisage the load flow consequences of all possible sequences of upgrades to an existing system, over a long time horizon, with stochastic evolutions of generation expansion, demand and fuel prices, is a task of unmanageable dimensionality. Furthermore, from a welfare maximizing perspective, the joint optimization of generation and transmission expansion has always been difficult to handle, and even more so in an age of unbundled ownerships where economic efficiency is sought through pricing signals for congestion, use of system and connections rather than via central planning. This pragmatic framework for analysis is perhaps most evident in the initial stage of TEP, which is the decision to seek permits. The process of building a line usually involves a relatively long permitting process of up to 10 years, followed by 1-2 years of actual construction. In comparison, the lead times to build new power plants are generally much shorter. This means that TEP must anticipate generation investments. However, new generation is a key element in the valuation of transmission investments. Therefore, quite often transmission projects can be withdrawn when, after a long permitting process, forecasts have not materialized as anticipated. This makes it particularly interesting to study TEP from a flexibility perspective.

Given the importance of TEP in power systems, there is a wide array of literature devoted to its resolution. The remaining of this section reviews concisely the main modeling options and solution 
techniques applied to this problem. With respect to the modeling of power flows, relatively simple transportation models (which only take into account Kirchhoff's First Law) reduce the computational requirements of the optimization (Marin \& Salmeron, 1998). Linearized DC power flows or hybrid models (where only existing lines abide Kirchhoff's Second Law) are the most widely applied (Binato, de Oliveira, \& de Araujo, 2001; Pereira, Pinto, Cunha, \& Oliveira, 1985). Most studies ignore losses, although a few take them into account either in an approximate or exact way (Braga \& Saraiva, 2005; Rezende, Leite da Silva, \& Honorio, 2009; Sánchez \& Ramos, 2005). More sophisticated grid modeling options usually evaluate a given transmission plan rather than performing optimal transmission expansion. A particularly interesting example is the study of reactive power and voltages in the network. These considerations are usually analyzed after an expansion plan has been proposed, and any possible problems detected are considered for a new iteration in the planning process.

The literature has applied a wide array of techniques to TEP, such as Linear Programming (LP) (Villasana, Garver, \& Salon, 1985), Mixed-Integer Programming (MIP) or non-classical methods like genetic algorithms (Miranda \& Proenca, 1998), simulated annealing (Romero, Gallego, \& Monticelli, 1995), greedy searches (Binato et al., 2001) or expert systems (Teive, Silva, \& Fonseca, 1998). However, most of these studies do not capture the dynamic, multi-stage nature of this problem, where decisions can be re-evaluated in light of the revealed uncertainties. Most research works consider a static version of the problem (Garver, 1970). A second group develops sequential static planning, with several time horizons (Oliveira, Binato, \& Pereira, 2007). Some others do carry out dynamic planning, although most of them focus on very small case studies and use heuristic methods with no optimality guarantee. Some of the most relevant techniques that have been applied in this context are Dynamic Programming (DP) (Vasquez, Styczynski, \& Vargas, 2008) and metaheuristics (Romero, Rider, \& Silva, 2007). Solving the dynamic problem is however unmanageable for realistic case studies.

ROV studies the dynamics of individual decisions (therefore, it does not provide with a global optimal plan) to provide guidance on immediate decisions in an uncertain context taking into account flexibility. We study the option value embedded in the permitting process, something that has not been taken into account in the existing static or dynamic TEP approaches (it is therefore a contribution of this paper) and can be used to guide the decision to request permits for the construction of new lines. Although the exact calculation of this option value in real systems would be unmanageable, we develop an approximation that is simple enough to be applied to large networks as demonstrated in the case study. In addition, our ROV approach generates additional interesting information for decision support, such as investment thresholds and probabilities of investment, which will be described in this document.

This paper is organized as follows. First, a stylized model for TEP is described in section II. Then, section III. briefly introduces ROV. Section IV. describes the decision process of transmission expansion. Section V. presents an stylized case study that demonstrates the proposed approach. After that, sections VI. and VII. describe the proposed approach. Section VIII. applies the approximation to the stylized case study. The real-sized case study and its results are described in section VIII. Finally, section X. presents conclusions.

\section{TRANSMISSION EXPANSION PLANNING}

TEP decisions are usually taken by a central planner, identified with the TSO (Transmission System Operator) in most regulations. This is justified by the fact that the transmission network is a natural monopoly, and as such has not been liberalized as, for instance, the power generation business has been. In addition, most works in the literature carry out centralized TEP with centralized cost-based operation, even when dealing with liberalized generation markets (Garver, 1970; Gupta, Shekhar, \& Kalra, 2012). 
This is due to the complexities that market modeling can bring into the problem together with the longterm time horizons involved in the problem. The number of references that consider competitive generation is limited (Bresesti, Capasso, Falvo, \& Lauria, 2003; Hongbo Sun \& Yu, 2000). There has been however some work done on decentralized expansion (Cagigas \& Madrigal, 2003; Contreras, 1997; Contreras \& Wu, 2000) and the impact of coalitions (Contreras \& Wu, 1999), although these works study specific transmission projects rather than the complete expansion plan for a given system.

Consistently, the classical formulation of the TEP problem selects the optimal network additions that minimize the expected value of the sum of first-stage (investment) and second-stage (operation) costs. However, although the operation of the system is carried out in a centralized way, the impact of deregulation in generation expansion planning is taken into account by means of stochastic scenarios. This section presents a stylized version of the optimization model used, which omits some details such as the calculation of losses (which is based on a piecewise linear approximation).

\section{A. Indices}

$i, j$ : nodes

$c$ : cable types

$E L, C L$ : existing and candidate lines respectively

$t$ : discrete time periods considered when lines can be installed. The first period (the decision period) and the last period in the analysis will be represented respectively as $D, T$. The time elapsed between two periods will be referred to as $E t_{t_{1}, t_{2}}$.

$\omega_{t}$ : possible system states (scenarios). Each scenario has different values for some of the parameters, specifically, the parameters that are considered uncertain.

\section{B. Parameters}

$D f_{t_{2}, t_{1}}$ : discount factor to evaluate a future cashflow corresponding to date $t_{2}$ in value terms of a closer date $t_{1}$. It is calculated as $D f_{t_{1}, t_{2}}=\mathrm{e}^{-\rho E t_{t_{1}, t_{2}}}$.

$\rho:$ discount rate $[\mathrm{pu}]$

$P^{\omega_{t}}$ : probability of the states. The uncertainty can be described via a scenario tree where the probability of a state $P^{\omega_{t}}$ depends on the previous state $P^{\omega_{t}}=F\left(\omega_{t-1}\right)$. For the sake of simplicity, we will omit this in the notation and use $P^{\omega_{t}}$ when referring to this probability.

$D u r_{t}$ : duration of the considered periods [h]

$I c_{i j c}:$ investment cost of a circuit [M€]

$D_{t, i}^{\omega_{t}}:$ demand at each node [MW]

Pnsc: penalty for power not served [M€/MWh]

$G c_{i}^{\omega_{t}}$ : generation cost [M€/MWh] 
$X_{i j c}:$ reactance of a circuit $[\mathrm{pu}]$

$\bar{F}_{t, i j c}^{\omega_{t}}, \bar{G}_{t, i}^{\omega_{t}}, \underline{G}_{t, i}^{\omega_{t}}$ : flow and generation limits respectively [MW]

$M_{t, i j c}:$ Big-M parameters

C. Variables

$x_{t, i j c}^{\omega_{t}}$ : cumulative decision to install a candidate investment between nodes $i$ and $j$ using cable type $c$ at time $t$ if the state is $\omega_{t}\{0,1\}$

$g_{t, i}^{\omega_{t}}:$ power generated at a node $[\mathrm{MW}]$

$p n s_{t, i}^{\omega_{t}}:$ power not served at each node [MW]

$f_{t, j i c}^{\omega_{t}}:$ flow through a circuit [MW]

$\theta_{t, i}^{\omega_{t}}:$ voltage angles at nodes [rad]

D. Objective function

The objective function minimizes the sum of investment and operation costs:

$$
\min \sum_{t=D}^{T} \sum_{\omega_{t}} P^{\omega_{t}} D f_{t, D}\left(i n v c_{t}^{\omega_{t}}+o p c_{t}^{\omega_{t}}\right)
$$

\section{E. Constraints}

Investment constraints:

$$
\begin{aligned}
& i n v c_{t}^{\omega_{t}}=\sum_{i j c \in C L} I c_{i j c}\left(x_{t, i j c}^{\omega_{t}}-x_{(\mathrm{t}-1), i j c}^{\omega_{t-1}}\right) \\
& x_{t, i j c}^{\omega_{t}} \geq x_{(t-1), i j c}^{\omega_{t-1}}
\end{aligned}
$$

Operation constraints, describing generation cost and power not served penalties:

$$
o p c_{t}^{\omega_{t}}=\operatorname{Dur}_{t} \sum_{i}\left(g_{t, i}^{\omega_{t}} G c_{i}^{\omega_{t}}+p n s_{t, i}^{\omega_{t}} P n s c\right)
$$

Kirchhoff's laws are the physical laws that govern how power flows across the network. In order to model TEP suitably, this rules should be incorporated into the model. Kirchhoff's first law establishes that power is balanced at each node: the sum of the incoming flows and the power generated is equal to the outcoming flows and the demand. A power-not-served term is included to cover the cases where the demand cannot be served in full.

$$
\sum_{j i c \in E L \cup C L} f_{t, j i c}^{\omega_{t}}-\sum_{i j c \in E L \cup C L} f_{t, i j c}^{\omega_{t}}+g_{t, i}^{\omega_{t}}=D_{t, i}^{\omega_{t}}-p n s_{t, i}^{\omega_{t}}
$$

Kirchhoff's second law establishes that the directed sum of the electrical potential differences (voltage) around any closed loop in the network is zero. We use the DCLF (Direct Current Load Flow) version of this rule, a widely used approximation that defines the flow though a transmission line as the difference 
of the voltage angles at the extreme nodes of the line (these angles are variables of the system operation) divided by the reactance of the line (which is a fixed parameter). We need to include different versions of this equation for existing and candidate lines, as this constraint should only be enforced if the line has been installed.

$$
\begin{aligned}
& f_{t, i j c}^{\omega_{t}}=\frac{\theta_{t, i}^{\omega_{t}}-\theta_{t, j}^{\omega_{t}}}{X_{i j c}} \quad i j c \in E L \\
& f_{t i j c}^{\omega_{t}}-\frac{\theta_{t, i}^{\omega_{t}}-\theta_{t, j}^{\omega_{t}}}{X_{i j c}} \geq-M_{t, i j c}\left(1-x_{t, i j c}^{\omega_{t}}\right), i j c \in C L \\
& f_{t, i j c}^{\omega_{t}}-\frac{\theta_{t, i}^{\omega_{t}}-\theta_{t, j}^{\omega_{t}}}{X_{i j c}} \leq M_{t, i j c}\left(1-x_{t, i j c}^{\omega_{t}}\right), i j c \in C L
\end{aligned}
$$

Generation and flow limits:

$$
\begin{aligned}
& -\bar{F}_{t, i j c}^{\omega_{t}} x_{t, i j c}^{\omega_{t}} \leq f_{t, i j c}^{\omega_{t}} \leq \bar{F}_{t, i j c}^{\omega_{t}} x_{t, i j c}^{\omega_{t}}, \quad i j c \in(C L \cup E L) \\
& \underline{G}_{t, i}^{\omega_{t}} \leq g_{t, i}^{\omega_{t}} \leq \bar{G}_{t, i}^{\omega_{t}} \\
& 0 \leq p n s_{t, i}^{\omega_{t}} \leq D_{t, i}^{\omega_{t}}
\end{aligned}
$$

Each possible system state $\omega_{t}$ assigns a value to the uncertain parameters that define the system. Some of these uncertainties can be described with probability distributions. These are random uncertainties. Examples of these are renewable production, hydro inflows or contingencies. Other sources of uncertainty (such as generation expansion, peak demand growth or fuel prices), cannot be accurately captured with a static probability distribution and are therefore more difficult to handle. We refer to these as dynamic or nonrandom uncertainties. In particular, the relationship between generation expansion planning (GEP) and TEP is complex and difficult to characterize, as there is some endogeneity between them (some transmission investments are dependent on the installation of new generation, and new generation cannot sell its power unless it is adequately connected to the network). Some authors have attempted to model this interrelationship. For instance, reference (Pozo, Sauma, \& Contreras, 2013) recently proposed a 3-level model that optimizes TEP, GEP and solves system operation respectively. However, most studies consider that GEP and TEP take a leader and a follower role respectively. This work focuses on TEP entirely and, consistently with most of the literature, GEP is considered an input for transmission planning. This input is defined through uncertain scenarios $\omega_{t}$.

\section{REAL OPTIONS AND THE VALUE OF WAITING TO INVEST}

Real options applies option valuation techniques to decision making under uncertainty. Financial options are instruments which grant the holder the right (but not the obligation) to buy (in the case of a call option) or sell (in the case of a put option) a given underlying asset at a future date (the expiry) at a specified price (the strike) (Hull, 2012). The holder pays the premium in exchange for the option. The expected payoffs (and hence the values) of a call and a put option are respectively:

$$
\begin{aligned}
& \mathrm{E}\left[N\left(Y_{T}-K\right) D f_{T, D}\right]^{+} \\
& \mathrm{E}\left[N\left(K-Y_{T}\right) D f_{T, D}\right]^{+}
\end{aligned}
$$


Where:

$[x]^{+}=\max \{0, x\}$ : denotes the positive values of a given function

$N$ : option notional

$K$ : strike

$Y_{T}$ : price of the underlying asset at expiry $T$

$D f_{T, D}$ : discount factor to value cash at expiry $T$ at decision date $D$.

Option valuation techniques assume a given model for the evolution of the underlying asset (in a financial context this often means a Geometric Brownian Motion, GBM) and obtain outputs such as option value or optimal exercise time. In some cases these magnitudes can be conveniently calculated as closed-form solutions.

A real option is similarly defined as the right (but not the obligation) to engage in a business initiative such as expanding capacity, deferring investment or abandoning a project (Dixit \& Pindyck, 1994; Luehrman, 1998). This technique provides with a framework to analyze the value of flexibility in management decisions.

Option Value $(\mathrm{OV})$, whether financial or real, has two main components, intrinsic value and time value:

$$
O V=I V+T V
$$

Intrinsic value $(I V)$ captures net present value. This amounts to the expected payoff that the holder would receive if he exercised the option at a given moment. In the case of a project, intrinsic value corresponds to its expected profit, which can be either positive or negative. Time value is the remaining constituent of the option value and reflects the potential for the payoff to increase before expiry. Time value is higher for longer option maturities and more volatile underlyings.

It has been proven that the solutions found using a real options approach coincide exactly with those of dynamic optimization at least in the cases where myopic decisions are optimal (Gahungu \& Smeers, 2011). There have been some applications of real options to power systems, in particular in GEP (Batista, Geber de Melo, Teixeira, \& Baidya, 2011; Bunn \& Larsen, 1994; Gahungu \& Smeers, 2011). Some authors have also studied some specific aspects of transmission investments using this technique, such as the optionality embedded in single lines (Saphores, Gravel, \& Bernard, 2004) or in selecting the size of interconnections (Fleten, Heggedal, \& Siddiqui, 2011) or the potential of distributed generation or FACTS for deferring investment in transmission lines (Blanco, Olsina, Garces, \& Rehtanz, 2011; Vasquez \& Olsina, 2007). We seek to apply ROV to valuing the flexibility embedded in requesting permits in TEP. We develop an approximation for option value that can be applied to realistic transmission systems.

\section{TRANSMISSION EXPANSION DECISIONS}

The expansion decisions that should be considered in TEP include:

- Starting a permitting process for building a new line. This step is relatively inexpensive but it is the most time consuming, taking usually from 7 to 10 years and even up to 15 years if problems arise. In general, the more jurisdictional areas are crossed by the line, the longer this procedure will take. In addition, public opposition or environmental concerns can get a project rejected. It is not possible to initiate the permitting process for all the potentially interesting lines (which are prohibitively many). A 
permit gives the right (but not the obligation) to build a line. It is possible to abandon permitted projects that once were in the medium-term plan if they are not optimal short-term expansion decisions.

- Adding a new circuit to an existing OHL (overhead line). This can take up to 1 year and can be undertaken relatively easily in most cases.

- Building a new line. This can take from 1 to 2 years and is the most expensive action in transmission expansion. The process of building an OHL consists of land clearing at the right-of-way, building temporary access roads, material delivering, foundation building, tower assembly and erection, conductor stringing, inspection and site restoration (Hydro Quebec, 2014). The relevant permits should be obtained before starting construction.

TEP in its classical form deals with determining the optimal network investments that minimize the expected total cost of the system (usually, the investment cost of network reinforcements minus the operation cost savings that can be achieved through a more efficient dispatch). However, the long permission process means that there is value in requesting the permit first and deciding whether to build or not later. The usual approach to TEP decides the optimal transmission plan and requests permits for the transmission lines contemplated in the plan. On the contrary, our approach requests two types of permits:

- For lines that bring substantial expected savings to the operation of the system.

- For lines that do not bring substantial expected savings now, but have a high potential to do so in the future, once the permit has been granted.

Our approach interprets expected and potential savings as:

- We define the intrinsic value of a transmission line as the expected operation savings that it can bring to the system minus investment cost. Intrinsic value coincides therefore with NPV and can be used to prioritize transmission lines according to their relative urgency (a transmission line that can bring relatively large savings should be prioritized).

- Option value identifies investments with a high potential upside. The permitting process should also be started for the most promising investments, identified by high option values.

This paper proposes expressions for intrinsic and option value that are simple enough to be applied to a problem as complex as TEP. In addition, as will be shown later, it is possible to calculate the threshold levels of the uncertain parameters that would make a given investment attractive using these definitions of intrinsic and option value. These calculations would determine by how much fuel prices should rise or how much new generation should be installed, so that a given transmission line should be built.

The main idea in this work is to consider that initiating a permitting process is a real option on investing in a transmission project at the future date when the permit is granted. ROV will be applied to calculate intrinsic value (expected operation cost savings minus investment cost) and option values (potential upside) for the candidate transmission investments considered. We therefore consider:

Consistently with this, The simplified decision dynamics that underlie the TEP problem are represented in Figure 1.

- First, permits are requested at the decision date $D$. These permits take around 10 years to be granted.

- The permits are granted at time $P$. Then, the decision to build them is taken, that is, the projects 
are either built or abandoned.

- If a transmission line is deemed suitable, then construction is started at time $P$ and finished at time $B$. This process takes around 1 year. In that case, the line is in operation for its full useful life (usually, 40 years).

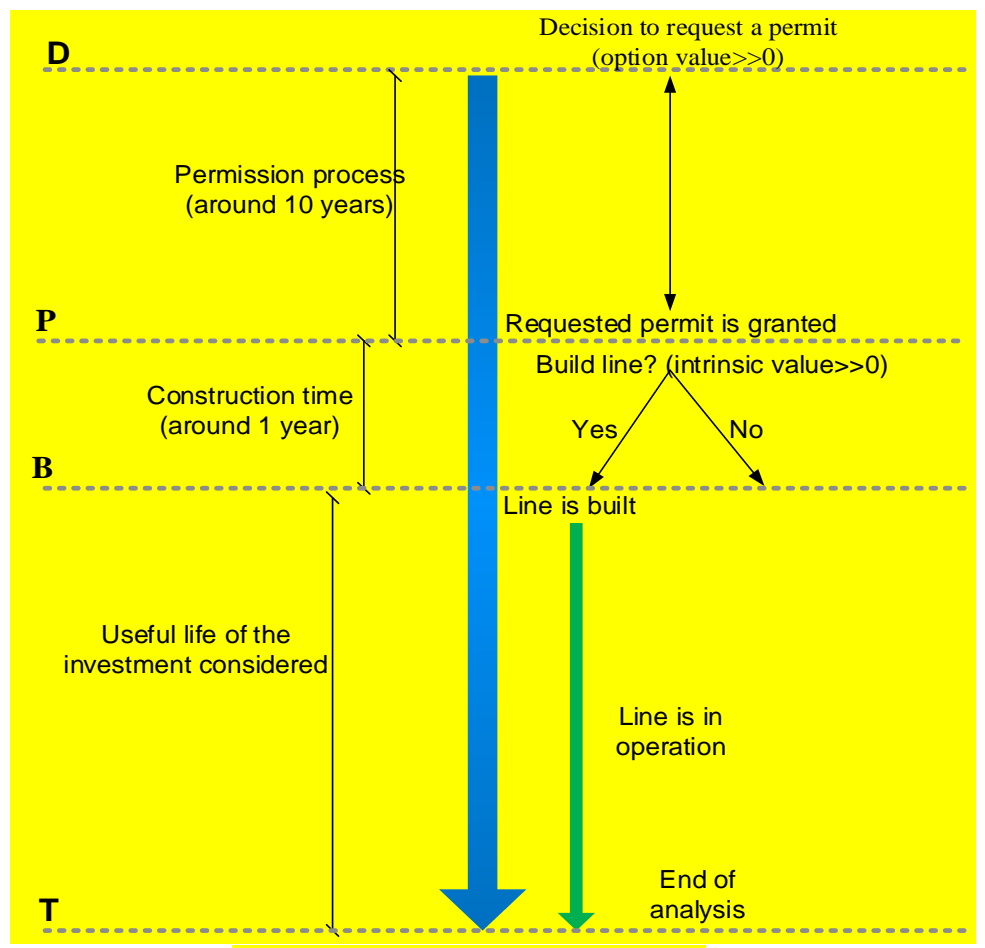

Figure 1. Decision dynamics.

In accordance with this, we can define several types of investments:

- Type A transmission lines will be defined as the ones with a high intrinsic value. As explained above, they should be treated as a priority.

- Type B transmission lines have a negative or low intrinsic value but a high option value. This means that they do not bring substantial expected savings. However, they have a high potential to do so once we take into account the possible evolutions of the system from time $D$ to time $B$ and the fact that we would only build them if they turn out to be profitable. This option value depends on the sensitivity of operation savings with respect to the parameters that describe the state of system and the volatility of these parameters. This value will be higher for higher sensitivities and volatilities.

- Type $C$ transmission lines have a negative or low intrinsic value and a low option value. They are not interesting neither as an immediate investment nor potentially in the future. Therefore, they should not be taken into account for future analyses.

\section{STYLIZED CASE STUDY}


This example shows a very simplified situation where the decision dynamics in TEP are more evident. The system is composed of a single demand. There are three projects that can be considered: A, B and C. The system is represented in Figure 2.

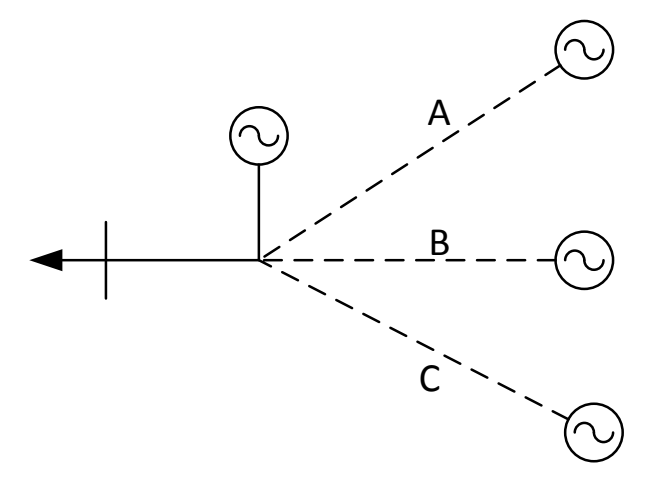

Figure 2. Example system.

The operation cost savings brought by each of the transmission projects, minus of operation costs (this is, the net savings, NS) are uncertain. For the sake of simplicity, we will assume that they are independent, follow a normal distribution and are revealed at time $P$, once the permit has been granted. If we had not assumed the latter, we should have modeled a further tree from the final nodes.

$$
\begin{aligned}
& N S=x_{A} N S_{A}+x_{B} N S_{B}+x_{C} N S_{c} \\
& N S_{A} \approx N\left(\mu_{A}, \sigma_{A}\right) \\
& N S_{B} \approx N\left(\mu_{B}, \sigma_{B}\right) \\
& N S_{C} \approx N\left(\mu_{C}, \sigma_{C}\right)
\end{aligned}
$$

where:

$x_{A}, x_{B}, x_{C}$ : binary variables that determine if the respective transmission project is built (1) or not (0).

All costs are expressed as an annual cost or an annual depreciation rate, so that no further amortization calculations or discounting is necessary. The parameters of the normal distributions are shown in Table 1. In order to build a scenario tree that is consistent with the normal probability distribution, the probabilities of each of the distributions being positive or negative has been calculated, together with their expected values conditional to being either positive or negative. For this, the expected value of the truncated normal distribution was used.

$$
\begin{aligned}
& P(N S>0)=\Phi\left(\frac{-\mu}{\sigma}\right) \\
& \mathrm{E}[N S / N S>0]=\left[\mu+\sigma \frac{\phi(-\mu / \sigma)}{1-\Phi(-\mu / \sigma)}\right][1-\Phi(-\mu / \sigma)]
\end{aligned}
$$




\begin{tabular}{|c|c|c|c|}
\hline & A & B & C \\
\hline$\mu$ & 1000 & 0 & -100 \\
\hline$\sigma$ & 10 & 5000 & 1 \\
\hline Prob (NS> 0) & 1 & 0,5 & 0 \\
\hline Prob (NS< 0) & 0 & 0,5 & 1 \\
\hline E(NS/NS > 0) & 1000 & 3989,42 & 0 \\
\hline E (NS/NS < 0) & 0 & $-3989,42$ & -100 \\
\hline
\end{tabular}

Table 1.Description of net operation cost savings.

The classical approach to the TEP problem would invest in projects that provide positive expected net savings and request for their permits. The decision trees can be seen in Figure 3.
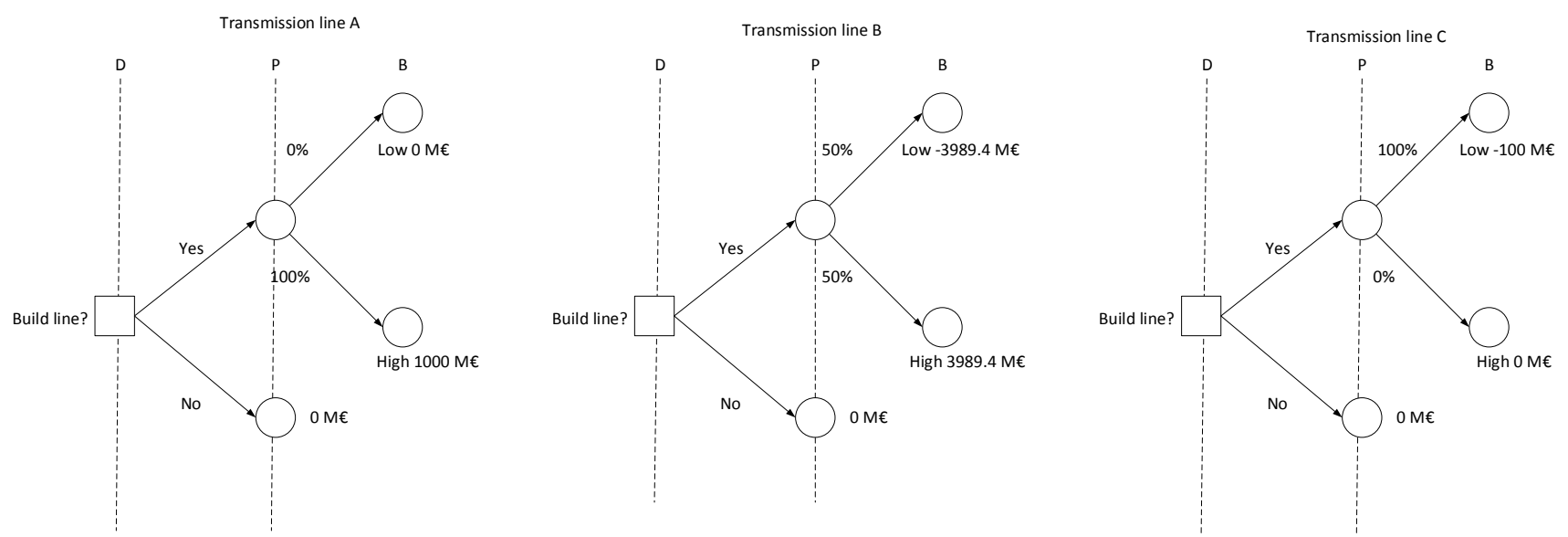

Figure 3. Classical decision tree. The planner decides whether to build or not the transmission lines at the decision date.

This would nean investing only on project $\mathrm{A}$ and getting an expected net saving of $1000 \mathrm{M} €$.

However, our proposal considers that permits are requested at the decision date $D$ but we only decide whether to build or not when the permit is granted, at date $P$. We assume that the cost of requesting a permit is negligible with respect of the building cost of the lines. 


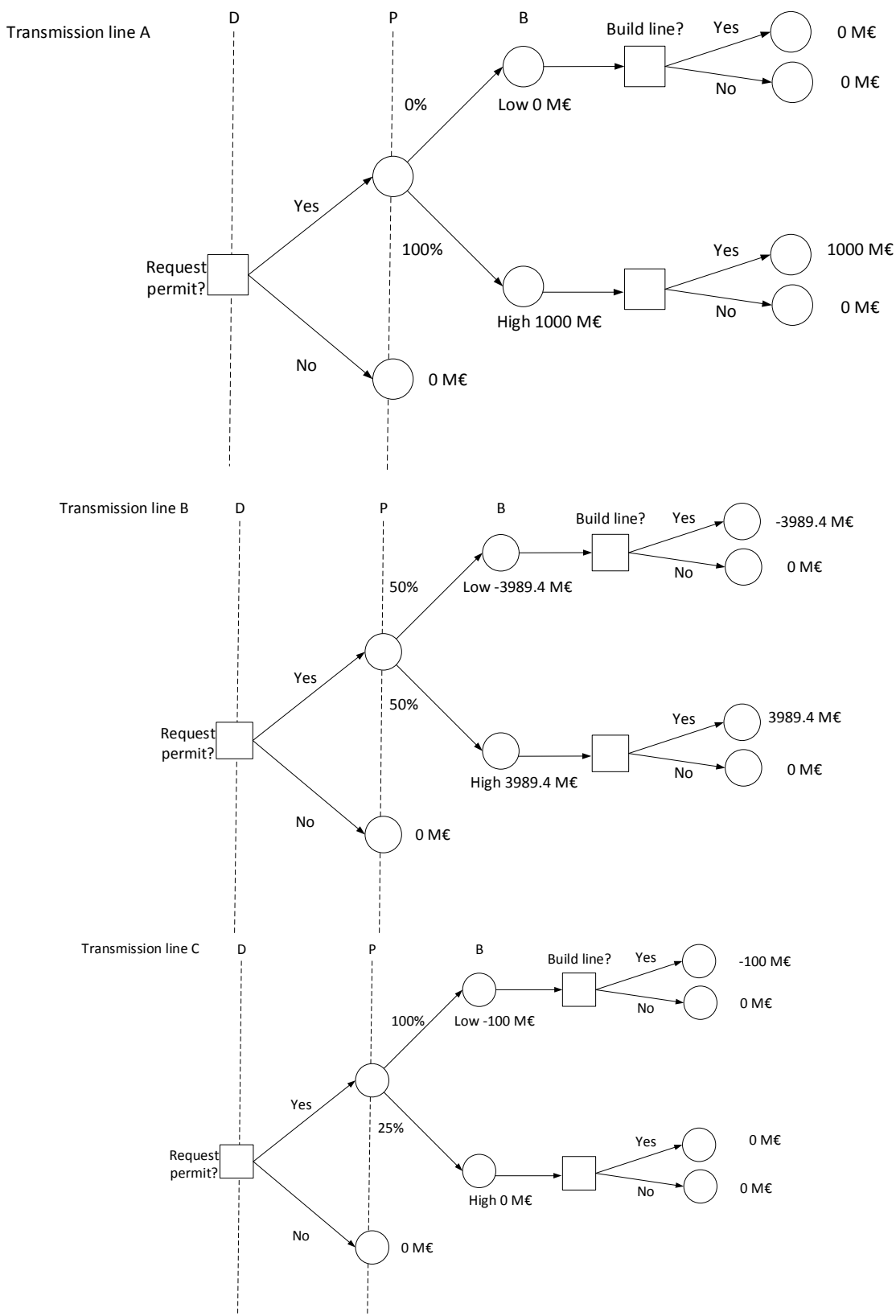

Figure 4. Proposed decision tree. Requesting a permit is equivalent to an option on building the capacity.

We consider that the intrinsic value of a transmission line is defined by the expected net savings it brings into the system. The option value embedded in requesting a permit can be calculated as the net savings taking into account that the line will only be built if it turns out to be profitable once the permit has been granted. In accordance with the decision trees above, the intrinsic and option values for the transmission lines are: 


\begin{tabular}{|l|cccc|}
\cline { 2 - 5 } \multicolumn{1}{c|}{} & $\mathbf{A}$ & $\mathbf{B}$ & $\mathbf{C}$ & Total \\
\hline Intrinsic Value $\mathbf{( M € )}$ & $1,000.0$ & 0 & 0 & $1,000.0$ \\
Option Value $\mathbf{( M € )}$ & $1,000.0$ & $1,994.7$ & 0,0 & $2,994.7$ \\
\hline
\end{tabular}

Table 2. Intrinsic and option values for the stylized case study.

Transmission line A has a high intrinsic value, it is very much in the money. Therefore, it should be in the optimal plan and its permit should be requested. Transmission line B is not in the money; if we decided to build it now, the expected operation cost savings would be negative. However, it has a high potential for savings in the future. We should therefore request the permit to build it, which we will only use if the high scenario materializes. However, transmission line $C$ will never be profitable. It has neither intrinsic nor option value. Consequently, it can be dropped from further analyses. In this illustrative case study, the expected profit from an options-based strategy is 2,994.7 M€, which is around two times larger than the expected profit from the classical approach, which amounts to only $1000 \mathrm{M} €$. As can be seen and contrary to the classical approach to TEP, the optionality embedded in requesting a permit has value and therefore it should be taken into account in the decision process. Rather than determining what lines to build at the decision date, the planner should request permits for the ones that present a high potential, and only decide whether to build them or not once the permit has been granted and construction can be started.

It is clear that the model presented in this stylized example is much simpler than the real TEP problem. In particular, for a realistic system:

- The number of generators is large.

- There are many uncertainties associated to the problem.

- These uncertainties do not necessarily follow a normal distribution.

- There are still uncertainties at the point when we decide whether to build the line or not.

- The complexity of the system means that, in order to calculate the expected operation cost savings we need to solve the problem defined in section II.

- Requesting a permit involves a cost.

As a result, calculating the intrinsic and option value of network investments is an extremely complex problem. However, we formulate the definitions of intrinsic and option value and develop an approximation so that they can be calculated in a real case study. We consider the full complexity of the network and the dispatch using the formulation in section II. In addition, we incorporate the uncertainties, although, in order to be able to extract a closed-form solution, we will assume that they follow a normal distribution. In addition, although requesting a permit does involve a cost, this cost is indeed negligible with respect to the system operation cost and the investment cost associated to 
transmission lines, so we will not consider it. In the rest of the paper, we present our approach and demonstrate it in a real case study. In accordance to it, the planner does not decide on which lines to invest at inception, but rather requests permits for the set of transmission lines with the highest potential and only decides whether to build them or not when the permit has been granted, which is assumed to happen 10 years afterwards.

\section{CAlCUlation OF INTRINSIC AND Option VALUE}

This section presents the definition of intrinsic and option value and the approximation proposed for its calculation. The analysis focuses on the optionality that is implicit in the permitting process. The simplified decision dynamics are:

$D$ : decision period. The decision to request permits is made at this period. The decision will be based on potential operation cost savings (option value).

$P$ : time period when the permit is granted (assumed to be around 10 years after the permit was requested). Once the permit has been granted, the decision to build the line or not is made. Lines with a sufficiently high intrinsic value (they bring high operation cost savings to the system) will be built.

$B$ : time period when the line is already built and in operation. This is assumed to happen 1 year after the decision to build the line was taken and the investment cost was realized.

$T$ : final time period in the analysis.

The intrinsic value of an investment is calculated as the expected cost savings that the investment would bring. It corresponds to the classical definition of project NPV. In the case of building a line, this means the difference in operation costs between a base case where the line is not installed and the situation where the line is in operation, minus the investment cost:

$$
I V\left(x_{D, i j c}\right)=\mathrm{E}\left[\sum_{t=B}^{T} \sum_{\omega} P^{\omega_{t}} D f_{t, D} o p c_{t}^{\omega_{t} / x_{t, j i c}^{\omega_{t}}=0}-\sum_{t=B}^{T} \sum_{\omega} P^{\omega_{t}} D f_{t, D} o p c_{t}^{\omega_{t} / x_{t, j i c}^{\omega_{t}}=1}-I c_{i j c} D f_{P, D}\right]
$$

Option value at the starting date is calculated assuming the line is only built if doing so results in net savings. The only difference between Eq. (15) and Eq. (16) is that Eq. (16) only adds the scenario where building the line presents a positive intrinsic value (its potential benefit).

$$
O V\left(x_{D, i j c}\right)=\mathrm{E}\left[\sum_{t=B}^{T} \sum_{\omega} P^{\omega_{t}} D f_{t, D} o p c_{t}^{\omega_{t} / x_{t, j i c}^{\omega_{t}}=0}-\sum_{t=B}^{T} \sum_{\omega} P^{\omega_{t}} D f_{t, D} o p c_{t}^{\omega_{t} / x_{t, i j c}^{\omega_{t}}=1}-I c_{i j c} D f_{P, D}\right]^{+}
$$

It should be noted that the definition above is consistent with a European option, which implicitly assumes that the planner can decide to build the line or not once the permit has been granted at time $P$, but not later. The planner will normally have further opportunities to build the line (for instance, yearly before the permit expires). This would lead to modeling a Bermudan option. However, permit expiration dates are very case dependant, so we choose to assume that the permit can be used at $P$ or abandoned, with no further actions taken.

It is important to note that, given the investment is discrete, the differences in operation costs are based on increments rather than marginal information. If an expansion plan has already been defined, a line can be canceled if it is not considered profitable once the permit has been granted. Option value reflects the possibility of canceling or deferring the project. This case inverts the calculation of expected savings: 


$$
O V\left(x_{D, i j c}\right)=\mathrm{E}\left[\sum_{t=B}^{T} \sum_{\omega} P^{\omega_{t}} D f_{t, D} o p c_{t}^{\omega_{t} / x_{t, i j c}^{\omega_{t}}=1}-\sum_{t=B}^{T} \sum_{\omega} P^{\omega_{t}} D f_{t, D} o p c_{t}^{\omega_{t} / x_{t, i j c}^{\omega_{t}}=0}-I c_{i j c} D f_{P, D}\right]^{+}
$$

\section{PROPOSED APPROXIMATION}

The exact evaluation of option value is complex, as it implies integrating costs across the probability distributions of all uncertain parameters, with each evaluated point demanding the resolution of system operation. Therefore, a feasible procedure is necessary.

\section{A. Operation cost approximation}

The proposed operation cost approximation will have to take into account several sources of uncertainty $\omega_{y t}$ (such as demand or fuel prices). Given that, once investment variables are fixed, the problem is convex, changes in operation cost when only one of the uncertain parameters changes can be exactly described with a piecewise linear function (Birge \& Louveaux, 1988). For small changes in the uncertain parameters, the changes in operation cost for a given scenario $\omega$ can be approximated by a linear function. The sensitivity of operation cost with respect to every uncertain parameter is expressed as:

$$
\delta_{y t}^{\omega_{t}}=\frac{\partial o p c_{t}^{\omega_{t}}}{\partial \omega_{y t}}
$$

For the sake of simplicity, hatted expressions will represent the expected values of variables or parameters when evaluated at the decision date $D$. For instance, $\hat{\omega}_{y t}^{0}$ represents the expected value of the uncertain parameter $\omega_{y t}^{0}$ at time $t$ when evaluated from the perspective of decision date $D$. The expected operation cost for parameter $\hat{\omega}_{y t}^{0}$ is therefore $\hat{o} p c_{t}^{\omega_{t}}=o p c_{t}^{\omega_{t}}\left(\hat{\omega}_{y t}^{0}\right)$.

A linear approximation of operation cost for a given scenario $\omega$ as a function of the uncertain parameters gives:

$$
o p c_{t}^{\omega_{t}}\left(Y_{t}^{y}\right)=\hat{o} p c_{t}^{\omega_{t}}+\sum_{y} \delta_{y t}^{\omega_{t}}\left(\omega_{y t}^{0}-\hat{\omega}_{y t}^{0}\right)
$$

It should be noted that $\delta_{y t}^{\omega_{t}}$, the sensitivities of operation cost, are marginal information that is readily available from the resolution of the system operation problem as described in II. For instance, the sensitivity to demand is the dual variable of Kirchhoff's first Law (Eq. 5), which coincides with nodal prices; the sensitivity with respect to generation capacity is the dual variable of the generation limit (Eq. 9); and the sensitivity to the price of a given fuel is the total consumption of that fuel. These sensitivities can also be calculated numerically for a small increment in the uncertain parameter.

\section{B. Expressions for intrinsic and option value}

The value of investing in line $x_{i j c}$ at decision date $D$ can be calculated as the expected value of operation cost savings (the difference in operation cost when the line is installed with respect to the base case where it is not installed) net of investment costs:

$$
I V\left(x_{D, i j c}\right)=\mathrm{E}\left[\sum_{t=B}^{T} \sum_{\omega_{t}} P^{\omega_{t}} D f_{t, D} o p c_{t}^{\omega_{t} / x_{t, j i c}^{\omega_{t}}=0}-\sum_{t=B}^{T} \sum_{\omega_{t}} P^{\omega_{t}} D f_{t, D} \hat{o} p c_{t}^{\omega_{t} / x_{t, j i c}^{\omega_{t}}=1}-I c_{i j c} D f_{P, D}\right]
$$


Option value computes the expected value of the investment conditional to it being positive at the time when the line can be built. If we use the operation cost approximation as a function of the base operation cost and the uncertainties:

$$
\begin{aligned}
& O V\left(x_{D, i j c}\right)=\mathrm{E}\left[\sum_{t=B}^{T} \sum_{\omega_{t}} D f_{t, D} P^{\omega_{t}}\left(\hat{o} p c_{t}^{\omega_{t} / x_{t, j i c}^{\omega_{t}}=0}-\hat{o} p c_{t}^{\omega_{t} / x_{t, j i c}^{\omega_{t}}=1}\right)+\right. \\
& \left.\sum_{t=B}^{T} \sum_{\omega_{t}} D f_{t, D} P^{\omega_{t}}\left(\sum_{y}\left(\delta_{y t}^{\omega_{t}, x_{t, j i}^{\omega_{t}}=0}-\delta_{y t}^{\omega_{t}, x_{t, j i c}^{\omega_{t}}=1}\right)\left(\omega_{y t}^{0}-\hat{\omega}_{y t}^{0}\right)\right)-I c_{i j c} D f_{P, D}\right]^{+}
\end{aligned}
$$

These expressions will guide the rest of this section.

\section{Description of the uncertainties}

For a given scenario, the value of uncertain parameters at time $B$ is assumed to follow a normal distribution centered on its forecast $\hat{\omega}_{y t}^{0}$. Its standard deviation $\sigma^{y}$ must be adjusted for time:

$$
\sigma^{* y}=\sigma^{y} \sqrt{E t_{t, D}}
$$

Fitting a normal distribution to the uncertainties is arguably good for sources of uncertainty such as fuel prices or peak demand growth, or generation capacities where increments can be very small (such as wind or solar) (Shimko, 1994). In many cases, these uncertainties are usually represented by means of lognormal distributions, so that the difference between the actual realization and the forecast can be reasonably approximated with a normal distribution (Hull, 2012).

$$
\omega_{y t}^{0}-\hat{\omega}_{y t}^{0} \approx \mathrm{N}\left(0, \sigma^{* y}\right)
$$

The approximation will not be as good when representing lumpier investments, such as nuclear capacity investments for instance. However, in a real-sized system there will be many uncertain factors involved, so the central limit theorem supports the approximation of normality. This assumption allows calculating closed-form solutions for option value, which calculation would otherwise be unmanageable for real-sized systems.

Substituting in the option value expression we obtain:

$$
\begin{aligned}
& O V\left(x_{D, i j c}\right) \approx \\
& \mathrm{E}\left[\sum_{t=B}^{T} \sum_{\omega_{t}} D f_{t, D} P^{\omega_{t}}\left(\hat{o p p} c_{t}^{\omega_{t} / x_{t, j, j}^{\omega_{t}}=0}-\hat{o} p c_{t}^{\omega_{t} / x_{t, j i c}^{\omega_{t}}=1}\right)+\right. \\
& \left.\sum_{t=B}^{T} \sum_{\omega_{t}} D f_{t, D} P^{\omega_{t}}\left(\sum_{y}\left(\delta_{y t}^{\omega_{t}, x_{t, j}^{\omega_{t}}=0}-\delta_{y t}^{\omega_{t}, x_{t, j i c}^{\omega_{t}}=1}\right) \mathrm{N}\left(0, \sigma^{* y}\right)\right)-I c_{i j c} D f_{P, D}\right]=\mathrm{E}\left[\mathrm{N}\left(\mu_{\text {Total }}, \sigma_{\text {Total }}\right)\right]^{+}
\end{aligned}
$$

where the parameters of the normal distribution describing the overall dynamics (total normal distribution) are $\mu_{\text {Total }}, \sigma_{\text {Total }}$.

A linear combination of normal distributions, where each normal $\mathrm{N}\left(\mu_{i}, \sigma_{i}\right)$ has a weight $w_{i}$ is defined as:

$$
\mathrm{N}\left(\mu_{L C}, \sigma_{L C}\right)=\sum_{i} w_{i} \mathrm{~N}\left(\mu_{i}, \sigma_{i}\right)
$$

The mean of the combination is: 


$$
\mu_{L C}=\sum_{i} w_{i} \mu_{i}
$$

The volatility of the combination can be obtained as:

$$
\sigma_{L C}=\sqrt{\sum_{i} w_{i} \sigma_{i}^{2}+\sum_{i, j \neq i} w_{i} w_{j} \sigma_{i} \sigma_{j} \rho_{i j}}
$$

It is convenient to define a constant correlation coefficient applicable to all pairs, known as equicorrelation:

$$
\begin{aligned}
& \rho=\sum_{i, j \neq i} c_{i j} \rho_{i j} \\
& c_{i j}=\frac{w_{i} w_{j} \sigma_{i} \sigma_{j}}{\sum_{i, j \neq i} w_{i} w_{j} \sigma_{i} \sigma_{j}}
\end{aligned}
$$

Therefore, for the particular case of option value:

$$
\begin{aligned}
& \mu_{T o t a l}=\sum_{t=B}^{T} \sum_{\omega_{t}} D F_{t, D} P^{\omega_{t}} \hat{o} p c_{t}^{\omega_{t} / x_{t, j i c}^{\omega_{i}}=0}-\sum_{t=B}^{T} \sum_{\omega_{t}} D F_{t, D} P^{\omega_{t}} \hat{o} p c_{t}^{\omega_{t} / x_{t, j i c}^{\omega_{t}}=1}-I c_{i j c} D f_{P, D}
\end{aligned}
$$

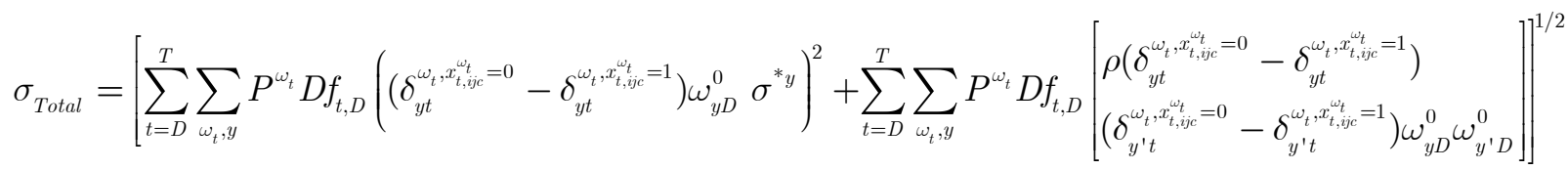

Once the parameters for the total normal distribution have been calculated, the option value can be derived as:

$$
O V\left(x_{D, i j c}\right)=\mathrm{E}\left[\mathrm{N}\left(\mu_{\text {Total }}, \sigma_{\text {Total }}\right)\right]^{+}
$$

This can be expressed as the expected value of a truncated normal probability distribution where only positive values are integrated. This can be calculated as:

$$
O V\left(x_{D, i j c}\right)=\mathrm{E}\left[\mathrm{N}\left(\mu_{\text {Total }}, \sigma_{\text {Total }}\right)\right]^{+}=\left[\mu_{\text {Total }}+\sigma_{\text {Total }} \frac{\phi\left(-\mu_{\text {Total }} / \sigma_{\text {Total }}\right)}{1-\Phi\left(-\mu_{\text {Total }} / \sigma_{\text {Total }}\right)}\right]\left[1-\Phi\left(-\mu_{\text {Total }} / \sigma_{\text {Total }}\right)\right]
$$

where $\phi$ and $\Phi$ denote the standard normal probability density function and the standard cumulative distribution respectively. This result is used to approximate the option value in a closed form and is applied in the case study described below.

Another useful result is the probability that a given investment will be carried out at a future date. This is referred to as the In-The-Moneyness or In-The-Money (ITM) probability of the option, and can be calculated as:

$$
\operatorname{ITMP}\left(x_{D, i j c}\right)=\mathrm{P}\left[\mathrm{N}\left(\mu_{\text {Total }}, \sigma_{\text {Total }}\right) \geq 0\right]=1-\Phi\left(-\mu_{\text {Total }} / \sigma_{\text {Total }}\right)
$$

In addition, the sensitivity of intrinsic value with respect to the uncertainties can be calculated as: 
$\operatorname{Sens}_{D, i j c, y}=\sum_{t=B}^{T} \sum_{\omega_{t}} D F_{t, D} P^{\omega_{t}}\left(\delta_{y t}^{\omega_{t}, w_{t, j i c}^{\omega_{t}}=0}-\delta_{y t}^{\omega_{i}, w_{t, j c}^{\omega_{t}}=1}\right)$

The key uncertainties $y^{*}$ for a given transmission line can be identified as the ones with the largest sensitivity absolute value $y^{*}=\arg \max _{y} \mid$ Sens $_{D, i j c, y} \mid$.

The thresholds for having a positive intrinsic value, assuming only one of the uncertainties is allowed to change, can be calculated as:

$T h_{D, i j c, y^{*}}=\frac{I V\left(x_{D, i j c}\right)}{\operatorname{Sens} s_{i j c, y^{*}}}$

Threshold values can be used to analyze the robustness of a decision with respect to changes in the scenarios. The usefulness of this is shown in the case study below.

\section{APPLICATION OF THE APPROXIMATION TO THE STYLIZED CASE STUDY}

In order to demonstrate the proposed approximation above in a very simplified setting, the developed approximation has been applied to the stylized case study.

a realistic case study will illustrate the potential benefits for a real system.

In this simplified example, operation cost savings are expressed as:

$$
N S=x_{A} N S_{A}+x_{B} N S_{B}+x_{C} N S_{C}
$$

Therefore, we can express operation cost as a constant (the initial operation cost value before any expansion decisions are made) minus net savings:

$$
o p c=K-\left(x_{A} N S_{A}+x_{B} N S_{B}+x_{C} N S_{C}\right)
$$

The uncertainties in this problem correspond to the net savings that can be obtained from the transmission lines:

$$
y \equiv\left\{N S_{A}, N S_{B}, N S_{C}\right\}
$$

As described in section $\mathrm{V}$. ,these uncertainties are assumed to follow a normal distribution.

$$
\begin{aligned}
& N S_{A} \approx N\left(\mu_{A}, \sigma_{A}\right) \\
& N S_{B} \approx N\left(\mu_{B}, \sigma_{B}\right) \\
& N S_{C} \approx N\left(\mu_{C}, \sigma_{C}\right)
\end{aligned}
$$

The parameters that describe these normal distributions are given in Table 3:

\begin{tabular}{|l|l|l|l|}
\hline & A & B & C \\
\hline$\mu$ & 1000 & 0 & -100 \\
\hline$\sigma$ & 10 & 5000 & 1 \\
\hline
\end{tabular}

Table 3. Parameters of the normal distributions. 
We can calculate the parameters to be input into the definitions of option value: average and standard deviation. The average is the difference in operation cost without and with the line minus the investment cost of the line, this is, the net savings:

$$
\begin{aligned}
& \mu_{\text {Total }, A}=\mathrm{E}\left(N S_{A}\right)=\mu_{A} \\
& \mu_{\text {Total }, B}=\mathrm{E}\left(N S_{B}\right)=\mu_{B} \\
& \mu_{\text {Total }, C}=\mathrm{E}\left(N S_{C}\right)=\mu_{C}
\end{aligned}
$$

We can also calculate the sensitivities of operation cost to be applied:

$$
\begin{aligned}
& \delta_{y}=\frac{\partial o p c}{\partial \omega_{y}} \\
& \delta_{N S_{A}}=\frac{\partial\left(K-\left(x_{A} N S_{A}+x_{B} N S_{B}+x_{C} N S_{C}\right)\right)}{\partial N S_{A}}=-x_{A} \\
& \delta_{N S_{B}}=\frac{\partial\left(K-\left(x_{A} N S_{A}+x_{B} N S_{B}+x_{C} N S_{C}\right)\right)}{\partial N S_{B}}=-x_{B} \\
& \delta_{N S_{C}}=\frac{\partial\left(K-\left(x_{A} N S_{A}+x_{B} N S_{B}+x_{C} N S_{C}\right)\right)}{\partial N S_{C}}=-x_{C}
\end{aligned}
$$

The only sensitivities that have a nonzero value are the ones that link a transmission line with its own net savings in the cases where the line has been built $(x=1)$ :

$$
\delta_{A}^{x_{A}=1}=\delta_{B}^{x_{B}=1}=\delta_{C}^{x_{C}=1}=1
$$

Because in this example we only have one factor for each transmission line, we get the following expression:

$$
\begin{aligned}
\sigma_{\text {Total }, A} & =\left(\delta_{A}^{x=0}-\delta_{A}^{x=1}\right) \sigma_{A}=\sigma_{A} \\
\sigma_{\text {Total }, B} & =\left(\delta_{B}^{x=0}-\delta_{B}^{x=1}\right) \sigma_{B}=\sigma_{B} \\
\sigma_{\text {Total }, C} & =\left(\delta_{C}^{x=0}-\delta_{C}^{x=1}\right) \sigma_{C}=\sigma_{C}
\end{aligned}
$$

Once the formulae to calculate intrinsic value, option value and in-the-money probability have been applied to the projects of building the transmission lines, the results obtained were the ones in

The results are given in Table 4. Intrinsic value, option value and in-the-money probability calculated for the projects.

\begin{tabular}{|l|r|r|r|}
\hline & \multicolumn{1}{|c|}{ A } & \multicolumn{1}{|c|}{ B } & \multicolumn{1}{|c|}{ C } \\
\hline IV & $1.000,0$ & 0,0 & $-100,0$ \\
\hline OV & $1.000,0$ & $1.994,7$ & 0,0 \\
\hline ITMP & 1,0 & 0,5 & 0,0 \\
\hline
\end{tabular}

Table 4. Intrinsic value, option value and in-the-money probability calculated for the projects.

As can be seen, because both approaches assume a normal distribution, the values calculated using the decision trees and the developed approximation match exactly. This small example demonstrates the 
proposed approach in a very simplified setting, where the complexities associated with TEP are largely ignored. We now present an application of options-based approach to a realistic setting.

\section{SPANISH CASE STUDY}

A realistic case study based on the Spanish system has been developed in order to test the feasibility of the proposed approach. It has been implemented as an additional feature to the existing TEPES model (Transmission Expansion Planning for an Electrical System), a more detailed description of which can be found in reference (Lumbreras \& Ramos, 2013). Transmission data as of 2008 were taken from publicly available ENTSO-e and REE E-SIOS cases (REE, 2012). The same E-SIOS cases were used to build forecasts for demand, generation capacities and renewable power generation as a percentage of installed capacity. The system is composed of 1084 nodes and 294 power plants (nuclear, coal, CCGTs, hydro, wind and solar). The existing transmission network is configured by 1505 lines and transformers. TEPES considers random renewable inputs and hydro inflows as well as individual contingencies in generation and transmission (taken from the E-SIOS data as well). These uncertainties are static, random uncertainties taken into account in the scenarios. HVDC transmission lines can be included in the analysis.

The ROV analysis considers dynamic uncertainty in demand, generation capacities and fuel and carbon prices. For the sake of simplicity, demand and capacities for a given technology were assumed to grow at the same rate at all nodes. Historical data were analyzed in order to extract values for the volatilities of the uncertain parameters. Market values were used for fuel prices, extracted from Bloomberg, using $12 \mathrm{~m}$ futures for Rotterdam coal, UK gas prices (the most relevant European price indicators) and EU Allowances for carbon prices respectively. Historical installed capacities for wind, solar and gas generators were taken from the system operator (Red Eléctrica de España, 2014, ). Where available, a 15 year data series was used. Annualized volatility was created from historical data as a rescaling of the standard deviation of consecutive increments:

$$
\begin{aligned}
\sigma_{i} & =\sqrt{n_{i} \frac{1}{N_{i}} \sum_{t=1}^{t}\left(\omega_{y, t}^{0}-\omega_{y, t-1}^{0}-\mu\right)^{2}} \\
\mu_{i} & =\frac{1}{N_{i}} \sum_{t=1}^{t}\left(\omega_{y, t}^{0}-\omega_{y, t-1}^{0}\right)
\end{aligned}
$$

where:

$N_{i}$ : number of observations

$n_{i}$ : number of observations that can be found in one year. For instance, if there is an observation every business day, $n_{i}=260$.

The resulting parameters can be seen in Table 4: 


\begin{tabular}{|l|r|}
\cline { 2 - 2 } \multicolumn{1}{l|}{} & $\begin{array}{r}\text { Annual } \\
\text { volatility }\end{array}$ \\
\hline Demand & $4.1 \%$ \\
\hline Generation capacities & \\
\hline Wind & $17.5 \%$ \\
\hline Solar & $57.7 \%$ \\
\hline Gas & $22.1 \%$ \\
\hline Fuel and carbon prices & \\
\hline Coal & $24.9 \%$ \\
\hline Gas & $53.4 \%$ \\
\hline Carbon & $77.4 \%$ \\
\hline
\end{tabular}

Table 5. Volatility of the uncertain parameters present in the case study.

The model described in sections II. and VII. was coded in GAMS and solved using CPLEX 12.1 as a solver, on a PC at $2.80 \mathrm{GHz}$ with 4 GB RAM running Microsoft XP 32 bits. The relative optimality tolerance used was $0.1 \%$. The CPU time used for the full set of calculations was $5860.4 \mathrm{~s}$ (less than 2 hours).

Following the proposed approach, intrinsic and option values are used to establish the priority of investments:

- Relatively high, positive intrinsic values signal transmission lines that are expected to bring savings if installed. Permits should be requested for them and they should be treated as priority projects.

- Transmission lines with a low intrinsic value but a relatively high option value have the potential of bringing high savings in the future. Permits should be requested for them and their value should be monitored during the permitting process.

A set of 74 promising candidate lines had their intrinsic and option values calculated. The optimal expansion plan identified by TEPES installed 24 of these lines. Intrinsic and option values were calculated for all candidates. As intrinsic and option values are dependent on operation cost, they also depend on the starting situation of the network. Three different situations have been considered in the case study:

- Initial state of the network, with no transmission additions

- Assuming the optimal expansion plan will be fully deployed. For the 24 transmission lines actually included in the plan, the values refer to the option of not building them or deferring their construction.

- An intermediate situation where only the most urgent investments are considered committed, and the others are only being studied. This is an interesting example as often long-term TEP selects only some of the most important investments while leaving the rest of the plan undefined. This assumes that only 4 lines are installed.

Table 6 shows the results of the case study. A threshold of $10 \mathrm{M} €$ has been established in order to filter 
investments. As expected, intrinsic and option values are much higher at the initial state of the network, where more improvements can be made. Conversely, if the base case is the optimal plan, option values are much lower. Moreover, by definition, all intrinsic values taking the optimal plan as a base case are negative. This is because changing anything from the optimal plan must result in a worse result (if there was a way of finding a better result, that plan would not be optimal). The intermediate situation presents intermediate results.

\begin{tabular}{|c|c|c|c|c|c|c|c|c|c|c|c|c|c|c|c|}
\hline & Initial stat & of the net & vork & & & Intermedia & & & & & Optimal & lan & & & \\
\hline & & & & & & & 1 & \| & & 1 & & & 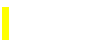 & & I \\
\hline Line & $\begin{array}{l}\text { Included } \\
\text { in plan? }\end{array}$ & $\begin{array}{c}\text { Intrinsic } \\
\text { Value }\end{array}$ & $\begin{array}{l}\text { Option } \\
\text { Value }\end{array}$ & $\begin{array}{l}\text { ITM } \\
\text { Prob }\end{array}$ & Priority & $\begin{array}{l}\text { Included } \\
\text { in plan? }\end{array}$ & $\begin{array}{c}\text { Intrinsic } \\
\text { Value }\end{array}$ & $\begin{array}{l}\text { Option } \\
\text { Value }\end{array}$ & $\begin{array}{l}\text { ITM } \\
\text { Prob }\end{array}$ & Priority & $\begin{array}{l}\text { Included } \\
\text { in plan? }\end{array}$ & $\begin{array}{c}\text { Intrinsic } \\
\text { Value }\end{array}$ & $\begin{array}{c}\text { Option } \\
\text { Value }\end{array}$ & $\begin{array}{l}\text { ITM } \\
\text { Prob }\end{array}$ & Priority \\
\hline 1 & 0 & 302,5 & 302,5 & 1,00 & High & 0 & 77,5 & 77,5 & 1,00 & High & 1 & $-25,4$ & 0,0 & 0,00 & \\
\hline 2 & 0 & 301,0 & 301,0 & 1,00 & High & 0 & 76,0 & 76,0 & 1,00 & High & 0 & $-4,5$ & 6,4 & 0,42 & \\
\hline 3 & 0 & 306,3 & 306,3 & 1,00 & High & 0 & 88,1 & 88,1 & 1,00 & High & 1 & $-0,7$ & 3,2 & 0,47 & \\
\hline 4 & 0 & 304,9 & 304,9 & 1,00 & High & 0 & 90,6 & 90,6 & 1,00 & High & 0 & $-5,3$ & 6,5 & 0,41 & \\
\hline 5 & 0 & 342,6 & 342,6 & 1,00 & High & 0 & 25,2 & 25,2 & 0,99 & High & 0 & $-3,3$ & 0,6 & 0,23 & \\
\hline 6 & 0 & 341,4 & 341,4 & 1,00 & High & 0 & 34,7 & 34,7 & 1,00 & High & 1 & $-9,2$ & 3,7 & 0,31 & \\
\hline 7 & 0 & 378,0 & 378,0 & 1,00 & High & 0 & 0,2 & 3,1 & 0,51 & & 0 & $-2,0$ & 2,2 & 0,40 & \\
\hline 8 & 0 & 376,9 & 376,9 & 1,00 & High & 0 & $-0,9$ & 1,9 & 0,44 & & 0 & $-3,1$ & 5,6 & 0,43 & \\
\hline 9 & 0 & 378,0 & 378,0 & 1,00 & High & 0 & 0,3 & 3,1 & 0,51 & & 0 & $-1,9$ & 2,2 & 0,40 & \\
\hline 10 & 0 & 376,9 & 376,9 & 1,00 & High & 0 & $-0,9$ & 2,0 & 0,44 & & 0 & $-3,0$ & 5,7 & 0,43 & \\
\hline 11 & 0 & 343,9 & 343,9 & 1,00 & High & 0 & 45,0 & 45,0 & 1,00 & High & 0 & $-1,8$ & 3,3 & 0,43 & \\
\hline 12 & 0 & 342,6 & 342,6 & 1,00 & High & 0 & 43,7 & 43,7 & 1,00 & High & 0 & $-3,1$ & 6,7 & 0,44 & \\
\hline 13 & 0 & 385,3 & 385,3 & 1,00 & High & 0 & $-1,0$ & 1,2 & 0,40 & & 0 & $-1,1$ & 2,6 & 0,44 & \\
\hline 14 & 0 & 384,3 & 384,3 & 1,00 & High & 0 & $-1,9$ & 0,8 & 0,31 & & 0 & $-2,1$ & 6,7 & 0,46 & \\
\hline 15 & 0 & 385,2 & 385,2 & 1,00 & High & 0 & $-1,0$ & 1,1 & 0,40 & & 0 & $-1,2$ & 2,6 & 0,44 & \\
\hline 16 & 0 & 384,2 & 384,2 & 1,00 & High & 0 & $-2,0$ & 0,8 & 0,31 & & 0 & $-2,1$ & 6,7 & 0,46 & \\
\hline 17 & 0 & 308,2 & 308,2 & 1,00 & High & 0 & 86,6 & 86,6 & 1,00 & High & 1 & $-20,1$ & 0,0 & 0,01 & \\
\hline 18 & 0 & 306,8 & 306,8 & 1,00 & High & 0 & 109,3 & 109,3 & 1,00 & High & 0 & $-5,0$ & 5,8 & 0,40 & \\
\hline 19 & 0 & 386,6 & 386,6 & 1,00 & High & 0 & $-2,7$ & 0,5 & 0,23 & & 0 & $-2,7$ & 4,9 & 0,43 & \\
\hline 20 & 0 & 385,6 & 385,6 & 1,00 & High & 1 & $-84,3$ & 0,0 & 0,00 & & 1 & $-81,9$ & 0,0 & 0,00 & \\
\hline 21 & 0 & 382,4 & 382,4 & 1,00 & High & 0 & 2,7 & 3,4 & 0,73 & & 0 & $-1,2$ & 6,6 & 0,47 & \\
\hline 22 & 0 & 381,4 & 381,4 & 1,00 & High & 0 & 1,6 & 2,5 & 0,66 & & 0 & $-2,2$ & 5,2 & 0,44 & \\
\hline
\end{tabular}




\begin{tabular}{|c|c|c|c|c|c|c|c|c|c|c|c|c|c|c|c|}
\hline 23 & 0 & 307,3 & 307,3 & 1,00 & High & 0 & 63,7 & 63,7 & 1,00 & High & 0 & $-3,7$ & 6,8 & 0,43 & \\
\hline 24 & 0 & 305,9 & 305,9 & 1,00 & High & 0 & 62,3 & 62,3 & 1,00 & High & 0 & $-5,1$ & 6,1 & 0,40 & \\
\hline 25 & 0 & 343,0 & 343,0 & 1,00 & High & 0 & 61,5 & 61,5 & 1,00 & High & 1 & $-67,2$ & 0,0 & 0,00 & \\
\hline 26 & 0 & 341,7 & 341,7 & 1,00 & High & 0 & 68,4 & 68,4 & 1,00 & High & 0 & $-3,8$ & 5,8 & 0,42 & \\
\hline 27 & 0 & 306,7 & 306,7 & 1,00 & High & 0 & 78,1 & 78,1 & 1,00 & High & 0 & $-3,0$ & 6,3 & 0,44 & \\
\hline 28 & 0 & 305,3 & 305,3 & 1,00 & High & 0 & 76,7 & 76,7 & 1,00 & High & 0 & $-4,4$ & 5,1 & 0,40 & \\
\hline 29 & 0 & 384,8 & 384,8 & 1,00 & High & 0 & 1,1 & 2,1 & 0,62 & & 0 & $-0,1$ & 8,0 & 0,50 & \\
\hline 30 & 0 & 383,9 & 383,9 & 1,00 & High & 0 & 3,7 & 4,2 & 0,79 & & 1 & $-76,0$ & 0,0 & 0,00 & \\
\hline 31 & 0 & 346,2 & 346,2 & 1,00 & High & 0 & 20,2 & 20,4 & 0,97 & High & 1 & $-4,7$ & 8,4 & 0,43 & \\
\hline 32 & 0 & 345,0 & 345,0 & 1,00 & High & 0 & 22,5 & 22,5 & 1,00 & High & 0 & $-4,5$ & 8,5 & 0,43 & \\
\hline 33 & 0 & 389,0 & 389,0 & 1,00 & High & 0 & $-0,7$ & 2,7 & 0,47 & & 1 & $-1,4$ & 9,0 & 0,48 & \\
\hline 34 & 0 & 388,4 & 388,4 & 1,00 & High & 0 & $-1,2$ & 1,9 & 0,42 & & 0 & $-2,0$ & 9,6 & 0,47 & \\
\hline 35 & 0 & 345,1 & 345,1 & 1,00 & High & 0 & 36,0 & 36,0 & 1,00 & High & 0 & $-1,9$ & 11,1 & 0,48 & Low \\
\hline 36 & 0 & 344,4 & 344,4 & 1,00 & High & 0 & 36,1 & 36,1 & 1,00 & High & 1 & $-48,1$ & 0,0 & 0,00 & \\
\hline 37 & 0 & 374,8 & 374,8 & 1,00 & High & 0 & $-1,9$ & 1,7 & 0,38 & & 0 & $-1,2$ & 11,1 & 0,48 & Low \\
\hline 38 & 0 & 374,1 & 374,1 & 1,00 & High & 0 & $-2,6$ & 0,8 & 0,29 & & 0 & $-1,9$ & 5,6 & 0,45 & \\
\hline 39 & 0 & 419,3 & 419,3 & 1,00 & High & 0 & 0,0 & 2,1 & 0,50 & & 0 & $-0,5$ & 13,2 & 0,49 & Low \\
\hline 40 & 0 & 419,1 & 419,1 & 1,00 & High & 1 & $-159,6$ & 0,0 & 0,00 & & 1 & $-125,9$ & 0,0 & 0,00 & \\
\hline 41 & 0 & 379,0 & 379,0 & 1,00 & High & 0 & $-2,2$ & 1,7 & 0,37 & & 0 & $-2,3$ & 13,6 & 0,48 & Low \\
\hline 42 & 0 & 378,1 & 378,1 & 1,00 & High & 0 & $-3,0$ & 0,7 & 0,25 & & 0 & $-3,2$ & 8,3 & 0,45 & \\
\hline 43 & 0 & 366,9 & 366,9 & 1,00 & High & 0 & 0,3 & 2,9 & 0,52 & & 0 & $-2,0$ & 12,9 & 0,48 & Low \\
\hline 44 & 0 & 365,9 & 365,9 & 1,00 & High & 0 & $-0,7$ & 1,5 & 0,44 & & 0 & $-3,1$ & 6,8 & 0,44 & \\
\hline 45 & 0 & 315,2 & 315,2 & 1,00 & High & 0 & $-3,9$ & 1,4 & 0,30 & & 1 & $-56,3$ & 0,5 & 0,04 & \\
\hline 46 & 0 & 313,8 & 313,8 & 1,00 & High & 1 & $-81,9$ & 0,0 & 0,00 & & 0 & $-5,3$ & 8,9 & 0,43 & \\
\hline 47 & 0 & 356,8 & 356,8 & 1,00 & High & 0 & 34,6 & 34,6 & 1,00 & High & 1 & $-1,5$ & 14,6 & 0,48 & Low \\
\hline 48 & 0 & 355,6 & 355,6 & 1,00 & High & 0 & 33,4 & 33,4 & 1,00 & High & 0 & \begin{tabular}{|c|}
$-4,8$ \\
\end{tabular} & 9,1 & 0,43 & \\
\hline 49 & 0 & 349,8 & 349,8 & 1,00 & High & 0 & \begin{tabular}{|l|}
$-1,4$ \\
\end{tabular} & 2,2 & 0,42 & & 0 & $-1,7$ & 15,0 & 0,48 & Low \\
\hline 50 & 0 & 348,9 & 348,9 & 1,00 & High & 0 & $-2,2$ & 0,9 & 0,31 & & 0 & $-2,6$ & 7,7 & 0,45 & \\
\hline 51 & 0 & 219,8 & 219,8 & 1,00 & High & 0 & $-2,9$ & 1,9 & 0,36 & & 1 & $-18,7$ & 7,3 & 0,31 & \\
\hline 52 & 0 & 218,7 & 218,7 & 1,00 & High & 1 & $-92,9$ & 0,0 & 0,00 & & 0 & $-4,0$ & 9,5 & 0,44 & \\
\hline 53 & 0 & 334,8 & 334,8 & 1,00 & High & 0 & 8,5 & 10,2 & 0,76 & Medium & 0 & $-3,2$ & 15,0 & 0,47 & Low \\
\hline
\end{tabular}




\begin{tabular}{|c|c|c|c|c|c|c|c|c|c|c|c|c|c|c|c|}
\hline 54 & 0 & 333,4 & 333,4 & 1,00 & High & 0 & 7,1 & 8,5 & 0,76 & & 0 & $-4,5$ & 7,7 & 0,43 & 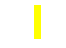 \\
\hline 55 & 0 & 348,3 & 348,3 & 1,00 & High & 0 & $-1,5$ & 2,1 & 0,41 & & 1 & $-1,8$ & 14,9 & 0,48 & Low \\
\hline 56 & 0 & 347,5 & 347,5 & 1,00 & High & 0 & $-2,4$ & 0,8 & 0,29 & & 0 & $-3,3$ & 9,8 & 0,45 & t \\
\hline 57 & 0 & 348,8 & 348,8 & 1,00 & High & 0 & 43,2 & 43,2 & 1,00 & High & 1 & $-2,3$ & 14,1 & 0,48 & Low \\
\hline 58 & 0 & 347,6 & 347,6 & 1,00 & High & 0 & 45,5 & 45,5 & 1,00 & High & 0 & $-4,7$ & 9,1 & 0,43 & \\
\hline 59 & 0 & 365,3 & 365,3 & 1,00 & High & 0 & 63,8 & 63,8 & 1,00 & High & 1 & $-31,1$ & 4,6 & 0,21 & \\
\hline 60 & 0 & 364,0 & 364,0 & 1,00 & High & 0 & 63,4 & 63,4 & 1,00 & High & 1 & $-75,6$ & 0,0 & 0,00 & \\
\hline 61 & 0 & 329,6 & 329,6 & 1,00 & High & 0 & 0,0 & 2,7 & 0,50 & & 0 & $-2,8$ & 15,5 & 0,47 & Low \\
\hline 62 & 0 & 328,6 & 328,6 & 1,00 & High & 0 & $-1,0$ & 1,3 & 0,41 & & 1 & $-7,6$ & 6,8 & 0,38 & 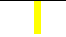 \\
\hline 63 & 0 & 330,2 & 330,2 & 1,00 & High & 0 & $-2,9$ & 1,9 & 0,36 & & 1 & $-16,1$ & 9,7 & 0,35 & D \\
\hline 64 & 0 & 329,0 & 329,0 & 1,00 & High & 0 & $-4,1$ & 0,8 & 0,24 & & 0 & $-4,6$ & 10,6 & 0,44 & Low \\
\hline 65 & 0 & 339,3 & 339,3 & 1,00 & High & 0 & 14,8 & 15,5 & 0,89 & High & 0 & $-3,6$ & 16,9 & 0,47 & Low \\
\hline 66 & 0 & 338,0 & 338,0 & 1,00 & High & 0 & 14,2 & 14,6 & 0,92 & High & 1 & $-36,7$ & 1,2 & 0,09 & \\
\hline 67 & 0 & 316,8 & 316,8 & 1,00 & High & 0 & $-0,5$ & 2,6 & 0,47 & & 1 & $-2,1$ & 16,5 & 0,48 & Low \\
\hline 68 & 0 & 315,8 & 315,8 & 1,00 & High & 0 & $-1,5$ & 1,3 & 0,38 & & 0 & $-3,8$ & 11,0 & 0,45 & Low \\
\hline 69 & 0 & 342,6 & 342,6 & 1,00 & High & 0 & 19,4 & 19,7 & 0,94 & High & 1 & $-16,2$ & 10,1 & 0,35 & Low \\
\hline 70 & 0 & 341,1 & 341,1 & 1,00 & High & 0 & 17,9 & 18,1 & 0,95 & High & 0 & $-5,5$ & 10,3 & 0,43 & Low \\
\hline 71 & 0 & 342,4 & 342,4 & 1,00 & High & 0 & 32,9 & 32,9 & 1,00 & High & 0 & $-3,6$ & 15,8 & 0,47 & Low \\
\hline 72 & 0 & 341,0 & 341,0 & 1,00 & High & 0 & 31,5 & 31,5 & 1,00 & High & 0 & $-5,0$ & 9,3 & 0,43 & \\
\hline 73 & 0 & 331,2 & 331,2 & 1,00 & High & 0 & 9,1 & 11,6 & 0,73 & Medium & 1 & $-4,8$ & 14,0 & 0,45 & Low \\
\hline 74 & 0 & 330,0 & 330,0 & 1,00 & High & 0 & 7,8 & 10,0 & 0,73 & Medium & 0 & $-4,7$ & 10,6 & 0,44 & Low \\
\hline Total & & $25.622,9$ & $25.622,9$ & 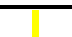 & & & & $1.721,5$ & 49,1 & & & 0,0 & 549,6 & & \\
\hline
\end{tabular}

Table 6. Full results for the Spanish case study for the initial state of the network, the intermediate situation and the optimal one.

High option values point to investments that should be monitored and for which a permit should be requested. For the lines not included in the expansion plan, a high option value signals a permit that should be requested. For lines already included in the plan, the values refer to the option to cancel them or deferring their construction. In many cases, this value is very close to zero. This means that the line seems so profitable under the current conditions that it will almost certainly be built. For instance, deferring line 60 has an option value of 0 , while deferring line 67 has an option value of $16.5 \mathrm{M} €$. The first kind of lines should be prioritized, while in the second case the focus should be on monitoring potential savings.

Overall, the total savings that using an options-based approach can bring can be approximated by total option value. Assuming that the base case follows the classical approach and installs the optimal 
transmission expansion plan, an options based approach would be able to get an additional 549.6 M€, which corresponds to the total option value in this case.

In addition, all the sensitivities with respect to the uncertain parameters are available as intermediate calculations. In the example of line 67, the key uncertainties are gas prices (with a sensitivity of $-2.42 \mathrm{M} €$ / $1 €$ increase in gas prices) and carbon prices (with a sensitivity of $-2.24 \mathrm{M} € / 1 €$ increase in carbon prices). This means that, although that line is currently in the optimal expansion plan, it will be withdrawn if gas or carbon prices rise sufficiently. For instance, the threshold increase in gas prices before the line becomes unprofitable can be calculated as the intrinsic value of not building it divided by the sensitivity of intrinsic value with respect to gas prices. This is:

$\operatorname{Th}\left(x_{t, i j c}, y^{*}\right)=\frac{I V\left(x_{t, i j c}\right)}{\operatorname{Sens}\left(y^{*}\right)}=\frac{-2.1}{-2.42}=0.87$

This means that if gas prices increase slightly $(0.87 €)$, then transmission line 67 will not be part of the optimal plan. The ITM probability represents the probability of the line being still profitable when the permit is granted. In this case, it was calculated as $50 \%$. This means that there is a $50 / 50$ chance that this line will be finally built.

This example shows how some investments that form part of the optimal plan are so sensitive to the uncertainties that they have a high probability of not being completed. However, some others (such as the example of line 60, where deferring investment had an option value of 0 ) seem robust with respect to the uncertainties and their assumed volatilities. This information can make it easier for planners to identify the key investments and focus on them while requesting additional permits for other lines that could bring important savings in some scenarios.

\section{CONCLUSIONS}

The transmission network supports the physical flows that underlie the operation of the power system. Therefore, Transmission Expansion Planning (TEP), that is, determining the reinforcements that should be added to the network, is a complex problem with deep implications. In particular, building a new line involves a long permitting process that takes around 10 years to complete. Therefore, transmission investments must anticipate the evolution of the uncertainties involved during that period. A particularly relevant example is the case of generation expansion, where deregulation means that there is no coordinated generation expansion plan and GenCos decide their generation expansion following price signals. On the contrary, given that transmission is a natural monopoly, transmission expansion decisions are taken centrally by the Transmission System Operator (TSO). The classical approach to TEP in this context is to determine the expansion plan and request the permits for the transmission lines that are part of this plan.

Our approach takes a different perspective and tries to take advantage of the fact that, once a permit has been granted, the TSO can decide whether to build the line or abandon the project. Therefore, we consider that requesting a permit is equivalent to an option on building the transmission line at the future date when the permit is granted. This leads to requesting permits not only for the transmission lines that bring high operation cost savings to the system (with a high NPV or high intrinsic value), but also for the ones that have a high potential to bring savings in the future. Calculating these intrinsic and option values would be unmanageable for realistic networks. However, we develop an approximation based on the sensitivities of operation cost with respect to the uncertainties that is simple enough to be applied to real systems. 
The benefits of the proposed approach and the validity of the developed approximation are illustrated in a stylized case study, which highlights the fact that there is value in requesting permits for lines with a negative NPV if they have a high option value and therefore have the potential to be highly beneficial in the future. The technique has also been applied to a realistic case study based on the Spanish system, where it identifies transmission lines with a high option value. In the case study, the expected operation cost savings In addition, the method calculates investment thresholds in terms of the uncertainties, for instance, beyond what fuel prices a transmission line is attractive. It also determines the in-the-money probabilities of the transmission lines, that is, the probability of they turning out to be profitable at the date when the permit is granted. This has also been illustrated in the Spanish case study. The case study shows that an options-based strategy outperforms the classical optimization approach as it exploits the flexibility embedded in the permitting process.

\section{REFERENCES}

Batista, F. R. S., Geber de Melo, A. C., Teixeira, J. P., \& Baidya, T. K. N. (2011). The carbon market incremental payoff in renewable electricity generation projects in brazil: A real options approach. Power Systems, IEEE Transactions on, 26(3), 1241-1251.

Binato, S., de Oliveira, G. C., \& de Araujo, J. L. (2001). A greedy randomized adaptive search procedure for transmission expansion planning. Power Systems, IEEE Transactions on, 16(2), 247-253.

Birge, J. R., \& Louveaux, F. (1988). Introduction to stochastic programming, Springer.

Blanco, G., Olsina, F., Garces, F., \& Rehtanz, C. (2011). Real option valuation of FACTS investments based on the least square monte carlo method. Power Systems, IEEE Transactions on, 26(3), 1389-1398.

Braga, A. S. D., \& Saraiva, J. T. (2005). A multiyear dynamic approach for transmission expansion planning and long-term marginal costs computation. Power Systems, IEEE Transactions on, 20(3), 1631-1639.

Bresesti, P., Capasso, A., Falvo, M. C., \& Lauria, S. (2003). Power system planning under uncertainty conditions. criteria for transmission network flexibility evaluation. Power Tech Conference Proceedings, 2003 IEEE Bologna, , 2. pp. 6 pp. Vol.2.

Bunn, D. W., \& Larsen, E. R. (1994). Assessment of the uncertainty in future UK electricity investment using an industry simulation model. Utilities Policy, 4(3), 229-236.

Cagigas, C., \& Madrigal, M. (2003). Centralized vs. competitive transmission expansion planning: The need for new tools. Power Engineering Society General Meeting, 2003, IEEE, , 2. pp. 1017 Vol. 2.

Contreras, J. (1997). A cooperative game theory approach to transmission planning in power systems. Working paper.

Contreras, J., \& Wu, F. F. (1999). Coalition formation in transmission expansion planning. Power Engineering Society 1999 Winter Meeting, IEEE, , 2. pp. 887 vol.2.

Contreras, J., \& Wu, F. F. (2000). A kernel-oriented algorithm for transmission expansion planning. Power Systems, IEEE Transactions on, 15(4), 1434-1440.

Dixit, A., \& Pindyck, R. (1994). Investment under uncertainty Princeton University Press.

Fleten, S. E., Heggedal, A. M., \& Siddiqui, A. (2011). Transmission capacity between norway and germany - a real options analysis. Journal of Energy Markets, 4(1), 121-147.

Gahungu, J., \& Smeers, Y. (2011). A real options model for electricity capacity expansion. CORE Discussion Paper,

Garver, L. L. (1970). Transmission network estimation using linear programming. Power Apparatus and Systems, IEEE Transactions on, PAS-89(7), 1688-1697.

Gupta, N., Shekhar, R., \& Kalra, P. R. (2012). A probabilistic transmission expansion planning methodology based on roulette wheel selection and social welfare. ArXiv Computer Science.

Hongbo Sun, \& Yu, D. C. (2000). A multiple-objective optimization model of transmission enhancement planning for independent transmission company (ITC). Power Engineering Society Summer Meeting, 2000. IEEE, , 4. pp. 20332038 vol. 4.

Hull, J. (2012). Options, futures and other financial derivatives (8th ed.). Boston, Pearson.

Hydro Quebec. Website hydro quebec., 2014.

Kaltenbach, J. C., Peschon, J., \& Gehrig, E. H. (1970). A mathematical optimization technique for the expansion of electric power transmission systems. Power Apparatus and Systems, IEEE Transactions on, PAS-89(1), 113-119. 
Latorre, G., Cruz, R. D., Areiza, J. M., \& Villegas, A. (2003). Classification of publications and models on transmission expansion planning. Power Systems, IEEE Transactions on, 18(2), 938-946.

Luehrman, T. A. (1998). Strategy as a portfolio of real options. Harvard Business Review, 76(5), 89-99.

Lumbreras, S., \& Ramos, A. (2013). Transmission expansion Planning Using an efficient version of Benders' decomposition. A case study. IEEE Power Tech, Grenoble (France).

Marin, A., \& Salmeron, J. (1998). Electric capacity expansion under uncertain demand: Decomposition approaches. IEEE Transactions on Power Systems, 13(2), 333-339.

Miranda, V., \& Proenca, L. M. (1998). Probabilistic choice vs. risk analysis-conflicts and synthesis in power system planning. Power Systems, IEEE Transactions on, 13(3), 1038-1043.

Oliveira, G. C., Binato, S., \& Pereira, M. V. F. (2007). Value-based transmission expansion planning of hydrothermal systems under uncertainty. Power Systems, IEEE Transactions on, 22(4), 1429-1435.

Pereira, M. V. F., Pinto, L. M. V. G., Cunha, S. H. F., \& Oliveira, G. C. (1985). A decomposition approach to automated generation/transmission expansion planning. IEEE Transactions on Power Apparatus and Systems, PAS-104(11), 3074-3083.

Pozo, D., Sauma, E. E., \& Contreras, J. (2013). A three-level static MILP model for generation and transmission expansion planning. Power Systems, IEEE Transactions on, 28(1), 202-210.

Red Eléctrica de España, 2014. Wwww.ree.es.

REE. E-SIOS (system for information from the system operator).

Rezende, L. S., Leite da Silva, A. M., \& Honorio, L. M. (2009). Artificial immune systems and differential evolution based approaches applied to multi-stage transmission expansion planning. Intelligent System Applications to Power Systems, 2009. ISAP '09. 15th International Conference on, pp. 1-6.

Romero, R., Gallego, R. A., \& Monticelli, A. (1995). Transmission system expansion planning by simulated annealing. Power Industry Computer Application Conference, 1995. Conference Proceedings., 1995 IEEE, pp. 278-283.

Romero, R., Rider, M. J., \& Silva, I. d. J. (2007). A metaheuristic to solve the transmission expansion planning. Power Systems, IEEE Transactions on, 22(4), 2289-2291.

Sánchez, P., \& Ramos, A. (2005). Modelling transmission ohmic losses in a stochastic bulk production cost model. IIT Working Paper,

Saphores, J., Gravel, E., \& Bernard, J. (2004). Regulation and investment under uncertainty: An application to power grid interconnection. Journal of Regulatory Economics, 25(2), 169-186.

Shimko, D. (1994). Options on futures spreads - hedging, speculation and valuation. Journal of Futures Markets, 14, 183-183-213.

Teive, R. C. G., Silva, E. L., \& Fonseca, L. G. S. (1998). A cooperative expert system for transmission expansion planning of electrical power systems. Power Systems, IEEE Transactions on, 13(2), 636-642.

Vasquez, P., \& Olsina, F. (2007). Valuing flexibility of DG investments in transmission expansion planning. Power Tech, 2007 IEEE Lausanne, pp. 695-700.

Vasquez, P., Styczynski, Z. A., \& Vargas, A. (2008). Flexible decision making-based framework for coping with risks existing in transmission expansion plans. Transmission and Distribution Conference and Exposition: Latin America, 2008 IEEE/PES, pp. 1-9.

Villasana, R., Garver, L. L., \& Salon, S. J. (1985). Transmission network planning using linear programming. Power Apparatus and Systems, IEEE Transactions on, PAS-104(2), 349-356. 